\title{
Temporary movements in stock prices
}

\author{
Jonathan Lewellen \\ MIT Sloan School of Management \\ 50 Memorial Drive E52-436, Cambridge, MA 02142 \\ (617) 258-8408 \\ lewellen@mit.edu
}

First draft: August 2000

Current version: March 2001

I thank Ken French and seminar participants at the February QWAFAFEW meeting in Boston for helpful comments and suggestions. 


\title{
Temporary movements in stock prices
}

\begin{abstract}
Mean reversion in stock prices is stronger than commonly believed. I show that 1-, 3-, and 5-year returns are negatively related to future returns over the subsequent 12 to 18 months. Reversals in 1year returns are the most reliable, with strong significance in both the full 1926 - 1998 sample and the more recent 1946 - 1998 period. The reversals are also economically significant. The full-sample evidence suggests that $25 \%$ to $45 \%$ of annual returns are temporary, reversing within 18 months. The percentage drops to between $20 \%$ and $30 \%$ after 1945. Mean reversion appears strongest in larger stocks and can take several months to show up in prices.
\end{abstract}




\section{Temporary movements in stock prices}

\section{Introduction}

The random walk hypothesis has a long history in asset pricing. Early studies, such as Kendall (1953) and Fama (1965), focused on daily or monthly stock returns. At these frequencies, autocorrelations are typically close to zero. Empirical research later turned to long-horizon returns to better isolate any transitory components in prices. In stark contrast to the earlier studies, this research found strong negative autocorrelation in returns. Fama and French (1988) estimate that mean reversion accounts for as much as $40 \%$ of the variation in 3- to 5-year returns for industry and size portfolios. Autocorrelations are strong for horizons of 2- to 6-years, and reversals tend to be most pronounced for smaller stocks. Their evidence suggests that prices contain a large temporary component (see also Poterba and Summers, 1988).

Many papers have challenged the reliability of Fama and French's results..$^{1}$ At least three statistical issues complicate their tests. First, it is well-known that autocorrelations are biased downward in finite samples. Because the effective sample sizes in long-horizon regressions are so small - a 60-year sample covers only 12 independent 5-year observations - the bias toward finding mean reversion can be substantial. Second, autocorrelations are typically estimated using overlapping monthly observations to increase the power of the tests. This procedure induces strong correlation among the residuals, but methods to adjust for the correlation are valid only in large samples. Third, the volatility of returns changes dramatically over time. Volatility was especially high before 1940 and a relatively small number of observations during the Depression era has a large effect on autocorrelation estimates. Taking these statistical issues together, the literature suggests four general conclusions about the autocorrelation of long-horizon returns:

(a) Long-horizon autocorrelations are either insignificant or, at best, marginally significantly negative.

The apparent significance reported by Fama and French (1988) is explained by a combination of the factors described above.

\footnotetext{
${ }^{1}$ See, especially, Richardson and Stock (1989), Kim, Nelson, and Startz (1991), and Richardson (1993).
} 
(b) To the extent that the autocorrelations are significant, the results are largely driven by the first 15 or 20 years of the sample, the Depression and World War II years. Autocorrelations are close to zero and insignificant after 1945 .

(c) Mean reversion, if real, shows up most strongly in small stocks. The equal-weighted market index is more negatively autocorrelated than the value-weighted index, and small-stock portfolios are more negatively autocorrelated than large-stock portfolios.

(d) Autocorrelations appear to be most negative for horizons of 3- to 5-years. Mean reversion over relatively short 1 - to 2 -year holding periods and relatively long 7 - to 10 -year holding periods is typically close to zero.

This paper presents new evidence on mean reversion in stock prices. My tests are based on regressions of monthly returns on lagged 1-, 3-, and 5-year returns. These regressions, like standard autocorrelations, test whether past returns contain information about future returns. They should be more powerful than full autocorrelations (5-year returns regressed on 5-year returns) because they focus on a shorter forecast horizon. Most stories for mean reversion would say that, if 5-year returns are negatively autocorrelated, they should be more highly correlated with next year's return than with the return in year 4 or 5 . If so, then a regression of monthly returns on lagged 5-year returns provides a better test for mean reversion. (Jegadeesh, 1990, formalizes this intuition in the context of Summer's, 1986, fads model.) A potential complication is that previous studies have identified strong short-run patterns in returns. Lo and MacKinlay (1988) show that weekly and monthly portfolio returns are positively autocorrelated, and Jegadeesh and Titman (1993) show that prices exhibit momentum over 3- to 12-months. This short-run momentum can dilute the appearance of long-horizon reversals. As a simple solution, I test for mean reversion for up to 18 months in the future, reporting statistics for individual months as well as joint tests across all months.

The results dispute, at least partially, all four assertions above. I find statistically reliable evidence that stock returns are negatively autocorrelated over 1-, 3-, and 5-year horizons. For the full sample, 1926 
- 1998, 1- and 5-year returns on size portfolios are strongly negatively correlated with returns over the next 12 to 18 months (results for 3-year returns are weaker). Based on bootstrap simulations, 1-year returns have significant predictive power for 8 of 12 size portfolios and 5-year returns have significant predictive power for 7 of the 12 portfolios. The average coefficient across the 12 portfolios, as well as the estimates for equal- and value-weighted market indices, are also significant. The autocorrelations are also economically large. Bias-adjusted estimates imply that $25 \%$ to $45 \%$ of annual stock price movements are temporary, reversing within 18 months. The estimates drop to between $10 \%$ and $15 \%$ for 5 -year returns. (The predictive power of 1- and 5-year returns is similar because 5-year returns are more volatile.)

Mean reversion remains strong after 1945, and the patterns across forecast horizons and size portfolios run counter to conventional wisdom. In the post-War period, 1-year returns have reliable predictive power, while the significance of 3- and 5-year returns diminishes. One-year returns are significant for 8 of the 12 size portfolios and for both equal- and value-weighted market indices. Further, mean reversion shows up most strongly in larger stocks. The autocorrelations are most negative for portfolios in the 3rd quartile, between the 50th and 75th percentiles of NYSE stocks, whereas the estimates are close to zero for the very smallest and very largest stocks. For example, the bias-adjusted 1year autocorrelation is -0.09 for the smallest portfolio, reaches a minimum of -0.26 for portfolio 9 , and drops off to -0.07 for portfolio 12 (the largest stocks). The estimates for portfolios 4 through 11 are statistically significant. Interestingly, reversals can take several months to show up in prices and remain strong for up to 18 months.

The use of monthly regressions largely explains why I find stronger reversals than previous studies. However, there is a second reason that reversals are strong for 1-year returns. To enhance comparison between the predictive power of 1-, 3, and 5-year returns, I use the same sample of monthly returns as the dependent variable in all regressions. This means that the first month in the full-sample regressions is July 1932 for all three predictive variables. In contrast, Fama and French (1988) began the tests with 1year returns in 1927, the tests with 3-year returns in 1929, etc. This small change has a surprisingly large impact on the results. In the first six years of data, $1926-1931$, the average autocorrelation of 1-year returns is a remarkable 0.64 for the size portfolios used here (the largest autocorrelation is 0.91). Because 
returns in this period are so volatile, they exert a strong influence on autocorrelations even with 60 years of data. I emphasize, however, that with the exception of the first few years, the autocorrelation estimates for 1-year returns are quite robust. The autocorrelations are significantly negative in the shorter $1946-$ 1998 period, and the estimates are similar if the sample begins in 1941, 1951, or 1961. Subperiod results for 1946 - 1971 and 1972 - 1998 provide additional evidence that reversals are significant.

On a methodological note, all of the tests here correct for time-varying volatility. In fact, the tests are actually more conservative than many studies; without the correction for heteroskedasticity, the evidence for mean reversion would be much stronger. In the full sample, for example, no simulation out of 5,000 produces coefficients on 1-year returns as large as the observed estimates for 6 of the 12 size portfolios. The actual p-values range from 0.018 to 0.032 after correcting for heteroskedasticity. While time-varying volatility is clearly important, it does not explain my results.

In short, stock prices seem to contain a large temporary component, consistent with evidence of Fama and French (1988). Contrary to their results, however, reversals occur fairly quickly and appear strongest for larger portfolios. The evidence also complements the recent findings of Lewellen (2000). He shows that the short-term momentum profits of Jegadeesh and Titman (1993) do not translate into positive autocorrelation in returns. Over 6- to 12-months holding periods, returns exhibit both negative autocorrelation and negative cross-serial correlation (correlation between a given stock and the lagged returns on other stocks). Together with the results here, the evidence suggests that mean reversion exists at all but the very shortest horizons.

The remainder of the paper is organized as follows. Section 2 discusses the empirical methodology and the small-sample properties of the test statistics. Section 3 describes the data and Section 4 presents the main empirical results. Section 5 concludes.

\section{Methodology}

Autocorrelation tests fall into two categories: regression-based tests, which look directly at serial correlation in returns, and variance-ratio tests, which measure how volatility changes as the holding period is lengthened. I focus on regression-based tests. This section discusses the regressions and the 
small-sample distribution of the test statistics.

\subsection{Regressions}

The goal is to test whether prices contain a temporary component. One approach is to simply estimate the autocorrelation of returns. Let $r_{t}^{k}$ equal the $k$-month return ending in month $t$. Fama and French (1988) estimate regressions of the form

$$
r_{t+k}^{k}=\alpha_{k}+\rho_{k} r_{t}^{k}+\varepsilon_{t+k}
$$

where $k$ varies from 12 to 120 months. To increase the power of the tests, Fama and French estimate eq. (1) using overlapping monthly returns. Since adjacent observations overlap by $k-1$ months, the regression residuals are strongly autocorrelated by construction. I discuss the statistical properties of these regressions below.

As an alternative to eq. (1), we can estimate exactly the same relation by breaking the dependent variable into the sum of $k$ one-month returns (assume continuous compounding):

$$
\begin{gathered}
r_{t+1}=\alpha_{1}^{\prime}+\beta_{1} r_{t}^{k}+v_{t+1}, \\
r_{t+2}=\alpha_{2}^{\prime}+\beta_{2} r_{t}^{k}+v_{t+2}, \\
\vdots \\
r_{t+k}=\alpha_{k}^{\prime}+\beta_{k} r_{t}^{k}+v_{t+k} .
\end{gathered}
$$

These equations regress monthly returns on lagged $k$-month returns. They are all the same except that the dependent variable ranges from one to $k$ months into the future. Because $r_{t+k}^{k}=r_{t+1}+r_{t+2}+\ldots+r_{t+k}$, the sum of the slope coefficients in the monthly regressions equals the full $k$-month autocorrelation from eq. (1), both in population and in sample.

Estimating a series of monthly regressions has a number of advantages over full autocorrelations. Monthly regressions are more informative because we can observe how the predictive power of $r_{t}^{k}$ changes with the forecast horizon. Most stories about mean reversion suggest that $r_{t}^{k}$ will be more strongly related to returns in the near future than in the distant future. For example, suppose that log 
prices are the sum of a random walk and an independent AR(1) process. Summers (1986) suggests this model as a parsimonious description of many behavioral theories; Fama and French (1988) argue that it is also consistent with time-variation in discount rates. In this case, it is easy to show that $r_{t}^{k}$ will be correlated most strongly with the return next month. (The slope coefficients in the monthly regressions decay geometrically.) As a consequence, the regression of $r_{t+1}$ on $r_{t}^{k}$ will have the greatest power to detect mean reversion in prices. Jegadeesh (1990) formalizes this intuition.

The argument that reversals will be strongest in month 1 suggests we should focus on the first regression, eq. (2a). That argument, however, depends critically on the AR(1) model for transitory price movements. Previous research suggests that an AR(1) model is not a good description of prices. Lo and MacKinlay (1988) show the weekly returns on size portfolios are strongly autocorrelated, and Jegadeesh and Titman (1993) show the prices exhibit momentum over 3- to 12-month horizons? Any short-term persistence in returns will tend to dilute the appearance of long-term reversals in month 1, implying that we might need to look several months into the future to detect mean reversion. The cutoff I choose, primarily because of space limitations, is 18 months. This cutoff is longer than any observed short-term patterns in returns, and it seems like a relatively long time to wait for mean reversion to show up. Shortening the period runs the risk of missing interesting patterns in the data, and lengthening the period reduces the power of the joint tests. For completeness, I also report full autocorrelations to compare with previous studies.

\subsection{Statistical tests}

The regressions, whether they use monthly or long-horizon returns, do not satisfy the standard assumptions of ordinary least squares (OLS). The predictive variable in the regression is stochastic and correlated with the lagged residuals. As a consequence, the slope estimate is biased downward and negatively skewed in finite samples.

\footnotetext{
${ }^{2}$ Note, however, that Jegadeesh and Titman do not show that returns are positively autocorrelated over 3- to 12month horizons; they find only that past winners (stocks in the top return decile) outperform past losers (stocks in the bottom decile) over these horizons. Lo and MacKinlay (1990) and Lewellen (2000) show that negative autocorrelation in returns is consistent with positive momentum profits.
} 
Consider, first, the full autocorrelation estimates of eq. (1). Kendall (1954) shows that autocorrelations are biased downward by approximately $1 / T$ under the null, where $T$ is length of the sample. Since the sample sizes with long-horizon returns are fairly short, regressions will be strongly biased toward finding mean reversion. For example, with 70 years of data in the full sample, the autocorrelation of 5-year returns is biased downward by approximately 0.07 . The bias is difficult to extend analytically to regressions with overlapping returns, but Monte Carlo simulations suggests it is similar.

To get the bias in monthly regressions, notice that they resemble the predictive regressions analyzed by Stambaugh (1999). Suppose that monthly returns are IID over time. The predictive variable in the regressions has first-order autocorrelation of $(k-1) / k$ because it equals the sum of $k$ monthly returns. Further, in a regression of $r_{t}^{k}$ on $r_{t-1}^{k}$, the residual variance equals $(2 k-1) / k$ times the variance of monthly returns. Using these observations and Stambaugh's eq. (18), the bias in the monthly slope is approximately

$$
E\left[\hat{\beta}_{1}-\beta_{1}\right] \approx-\frac{4 k-3}{2 k-1} \frac{1}{T}
$$

where $T$ is the number of monthly returns. For large $k$, the downward bias is roughly $2 / T$; the bias depends primarily on the sample size, not on the holding period of the predictive variables. Although the monthly regressions do not strictly fit into Stambaugh's framework, Monte Carlo simulations suggest that eq. (3) provides a reasonable approximation. (Specifically, it is a good approximation for the regression at lag one; the bias drops off as the lag increases.)

I have included the analytical formula primarily as a reference. Since the distribution is also negatively skewed, the statistical tests actually rely on simulations. The simulations use the randomization technique of Kim, Nelson, and Startz (1991). In each simulation, the historical sample of returns is randomly re-shuffled to eliminate any time-series patterns in the data. Thus, the simulations generate artificial time-series of returns under the null, while at the same time maintaining the unconditional distribution of returns. I estimate the regressions for each re-shuffled series, and an empirical distribution is constructed by repeating the process 5,000 times. The statistical significance of 
any coefficient is simply the fraction of simulations that are more extreme than the actual estimates. This randomization technique is similar to bootstrap simulations except that monthly returns are sampled without replacement.

Unfortunately, the simulations have an important limitation: they eliminate any time-varying volatility in the data. If volatility changes over time, the simulations might significantly underestimate sampling variation in the estimates. This concern is especially severe if volatility is correlated with past returns, for which there is strong evidence (e.g., Campbell and Hentschel, 1992). There are two possible ways around this problem. First, we can generate returns with time-varying volatility, but then we must make strong assumptions about the way volatility changes over time and across portfolios. An easier solution is to draw inferences based on White's (1980) t-statistics. That is, I compare the observed tstatistic (slope estimate divided by White's standard error) to its simulated distribution. White's standard errors are, of course, consistent estimators under very general forms of heteroskedasticity. As long as the distribution of the t-statistic is not very sensitive to the true form of volatility - and evidence in Jegadeesh (1990, appendix B) suggests it is not - the simulated distribution should be accurate without having to model the volatility process.

Heteroskedasticity also complicates the joint tests. The empirical tests report, in addition to statistics from individual regressions, joint tests across portfolios and across months. Because the simulations focus on t-statistics, I require an estimate of the covariances among regressions. To simplify the task, I use exactly the same time period for the dependent variables in all regressions (regardless of the lag). Thus, all regressions have the same number of observations and their residuals line up together in time. Heteroskedastic-consistent covariance estimates are then a straightforward generalization of White's standard errors $\$$

\section{Data and descriptive statistics}

The empirical tests focus on size portfolios. Much research finds that size is an important charac-

\footnotetext{
${ }^{3}$ Let $\beta_{i}$ and $\beta_{j}$ be estimates from any two regressions and $X_{i}$ and $X_{j}$ be the corresponding matrices of independent variables. Then $\operatorname{cov}\left(\hat{\beta}_{i}, \hat{\beta}_{j}\right)=\left(X_{i}^{\prime} X_{i}\right)^{-1} X_{i}^{\prime} E_{i} E_{j} X_{j}\left(X_{j}^{\prime} X_{j}\right)^{-1}$, where $E_{i}$ is a diagonal matrix constructed from
} 
teristic in asset pricing. Small stocks typically have higher risk and expected returns than big stocks, but lower liquidity and institutional ownership. These differences suggest that mean reversion might also vary with size. For example, Lee, Shleifer, and Thaler (1993) argue that investor sentiment is more likely to affect small stocks because they are held disproportionately by individual investors. If so, then small stocks should exhibit stronger reversals.

The portfolios are formed from all NYSE, Amex, and NASDAQ stocks on the Center for Research in Security Prices (CRSP) database. Each month, stocks are sorted into 12 size portfolios based on the market value of equity in the previous month. Following Fama and French (1988), the breakpoints are given by equally-spaced NYSE percentiles. I use NYSE percentiles to avoid dramatic changes in the portfolios as Amex and NASDAQ stocks enter the sample (in 1962 and 1973, respectively). It also helps reduce the fraction of market value in the largest portfolios. I calculate value-weighted returns for the portfolios from 1926 - 1998, and report tests both for the full sample and the shorter 1946 - 1998 period. Stock returns were extremely volatile prior to 1940 , and previous research suggests that those years can have a large impact on the results.

Table 1 shows descriptive statistics for the portfolios. There is considerable cross-sectional variation in the portfolios, with most characteristics varying monotonically with size. In the full sample, average monthly returns range from $0.97 \%$ for the largest stocks to $1.87 \%$ for the smallest stocks. Standard deviations range from $5.19 \%$ to $11.71 \%$. The differences across portfolios are much less pronounced after 1945 because small stocks have lower average returns and volatility. The spread in average returns drops to $0.17 \%$ and the spread in volatility drops to $2.08 \%$. Notice, also, that the number of firms and the fraction of market value vary greatly across portfolios. The smallest portfolio contains roughly $40 \%$ of the firms but less than $1 \%$ of total market value.

The table also reports descriptive statistics for equal- and value-weighted market indices and for the average size portfolio. The equal- and value-weighted indices are self-explanatory, but the average size portfolio might need additional explanation. It is simply a portfolio formed by equally-weighting the 12 size portfolios. This index provides, in some ways, a better measure of average returns. Comparing the

regression $i$ 's residuals. See White (1984). 
three indices, the equal-weighted index tends to overweight small stocks, by virtue of their large numbers, and looks a lot like the smallest few portfolios. The value-weighted index, in contrast, is made up primarily of the largest one or two size portfolios. The average size portfolio fits somewhere in the middle. I report evidence for these three indices in addition to the size portfolios.

\section{Testing for mean reversion}

The empirical tests are based on the regressions described in Section 2. The test explore which holding periods have the greatest forecasting power and how quickly mean reversion begins to show up in prices.

\subsection{Full autocorrelations}

Before turning to the monthly regressions, Table 2 shows full autocorrelations for comparison to previous studies. I report estimates for 1-, 3-, and 5-year returns. These holding periods are chosen to provide a fairly wide range of evidence, but hopefully not to overwhelm the reader with numbers. (The volume of numbers grows quickly when we get to the monthly regressions.) I have repeated the tests with 6-month returns, on the short end, and 7-year returns, on the long end, and find substantially the same patterns.

The table reports bias-adjusted autocorrelations and Newey-West standard errors. The regressions use overlapping monthly returns, so the number of lags for the Newey-West standard errors equals the overlap in the dependent returns. The bias and significance levels are obtained from simulations (see Section 2.2), while the standard errors are estimated from the actual regressions. Recall that the statistical tests are based on the distribution of Newey-West t-statistics as a way to control for time-varying volatility.

The autocorrelations are largely consistent with earlier studies. There is some indication of reversals but the evidence is weak. In the full sample, the bias-adjusted autocorrelations in 1-year returns are close to zero, ranging from -0.13 to 0.01 , and nowhere significant. The estimates for 3 - and 5-year returns drop substantially, with most between -0.10 and -0.30 . The average autocorrelation in 3 -year returns is -0.22 , 
but only the estimate for portfolio 7 is significant at the 5\% level (one-sided). For 5-year returns, the autocorrelations are significantly negative for portfolios $4-7$ and for the equal-weighted index (estimates between -0.26 and -0.34 ). Overall, however, mean reversions is only marginally significant: reversals are close to zero for the largest and very smallest stocks, and the average estimate across the 12 size portfolios is not significant for any holding period. That message is similar to the conclusions in the literature $4^{4}$

Panel B suggests that reversals in 3- and 5-year returns disappear after 1945. The 3-year autocorrelations range from -0.12 to 0.14 and the 5 -year autocorrelations range from -0.17 to 0.30 . None of the estimates is significantly different from zero. Somewhat surprisingly, annual returns show a hint of mean reversion. The average autocorrelation is -0.18 , and the estimates for portfolios 7 and 9 are significantly negative, equal to -0.23 and -0.26 . However, none of the market indices nor the average coefficient across the 12 size portfolios is significant. Again, the general conclusions from Panel B are consistent with previous evidence. Full autocorrelations provide little evidence of reversals once we skip the Great Depression.

\subsection{Monthly regressions, $1926-1998$}

In Section 2, I argued that monthly regressions provide a better way to test for mean reversion (see also Jegadeesh, 1990). They should be more powerful than full autocorrelations and they better isolate reversals in individual months. I first present evidence for the full sample and later test for mean reversion after 1945.

Table 3 reports the full-sample regressions. The predictive variables are either 1-, 3-, or 5-year cumulative past returns (Panels A, B, and C, respectively). For each portfolio, I estimate:

\footnotetext{
${ }^{4}$ Quantitatively, 1-year autocorrelations in Panel A tend to be more negative, while 3- and 5-year autocorrelations tend to be less negative, than those of Fama and French (1988). Also, reversals in the smallest stocks are much smaller here. The main reason for these differences is that I use raw returns while they use continuouslycompounded returns. The difference is less important after 1945 because return volatility diminishes, especially for the smallest stocks.

${ }^{5}$ The autocorrelations for 1-year returns in Panel B are more negative than those of Fama and French (1988). The difference seems to be explained by several factors: I use value-weighted portfolios of all stocks (instead of equal-weighted portfolios of NYSE stocks), raw returns (instead of continuously-compounded returns), and a longer sample (1946 - 1998 instead of 1941 - 1985).
} 


$$
r_{t+h}=\alpha_{h}+\beta_{h} r_{t}^{k}+v_{t+h}
$$

where $h$ varies from 1 to 18 . Because of space limitations, the table reports the sum of the slope estimates for adjacent months, $\beta_{1}+\beta_{2}, \beta_{3}+\beta_{4}$, etc., rather than individual estimates. Again, bias and significance levels are obtained from simulations, while standard errors are estimated from the actual data 6 As mentioned earlier, all regressions use the same set of monthly returns for the dependent variable, regardless of the time lag or the predictive return. Thus, the first dependent return in all regressions is July $1932(1926+5$ years +18 months $)$.

The results in Table 3 are striking. Consider, first, the regressions with 1-year returns. Panel A shows that 1-year returns are strongly negatively correlated with returns over the subsequent 18 months. The table reports the raw estimates multiplied by 100 , so the numbers can be interpreted as the percentage of past returns that reverse in any given period. The last column shows that, on average, $30 \%$ of annual returns reverse over the next 18 months. The temporary component of returns is close to zero for the smallest stocks, but it grows to $-44.9 \%$ for portfolio 10 . The estimate is between $25 \%$ and $45 \%$ for portfolios $4-12$ and the three market indices. These coefficients imply dramatic time-variation in expected returns. Using the point estimates in Panel A, forecasts of 18-month returns have a standard deviation of $9.4 \%$ for the average portfolio.

Statistically, 1-year returns seem to have predictive power for at least 14 months. The estimates for months $3-4$ and months $9-14$ are significantly negative for nearly all portfolios. The average coefficient for the 12 size portfolios, as well as the estimates for the three market indices, are also significant in these months. More generally, all forecast horizons consistently suggest mean reversion in returns, with most estimates at least one standard error below zero. The last column reports the sum of the coefficients across all 18 months. The sum is significantly negative for 8 of the 12 size portfolios and all three market indices.

To borrow a line from Fama and French (1988), there is little evidence in the literature that

\footnotetext{
${ }^{6}$ I run a separate simulation for each coefficient in the table. As an aside, simple bias-adjusted t-statistics (biasadjusted slopes divided by their standard errors) give a reasonable picture of statistical significance. The monthly regressions are much better behaved than full autocorrelations.
} 
foreshadows these results. There are two main differences between the monthly regressions and the autocorrelations in earlier studies. First, the monthly regressions extend the forecast horizon out to 18 months. Table 3 shows that mean reversion can take many months to show up in prices, so 1-year autocorrelations miss much of the reversals. Within the first eight months, only the estimates for months 3 and 4 are reliably different from zero. Reversals again become significant in month 9 and remain significant until month 14 . In fact, $34 \%$ of the total reversal occurs after month 12 for the average portfolio. Standard autocorrelations miss these patterns and they completely neglect reversals that occur after month 12.

The second main difference is the sample period. For the monthly regressions, the sample of dependent returns begins in July 1932. I use the same sample of dependent returns to enhance comparison between 1-, 3-, and 5-year returns and to simplify the statistical tests. The 1-year autocorrelations in Table 2, however, begin in 1927 to be consistent with the tests of Fama and French (1988). This minor difference has a surprisingly large impact on the estimates. In the first six years of data, 1926 - 1931, the autocorrelation of annual returns is a remarkable 0.64 for the average size portfolio. Because these returns are so volatile, they strongly attenuate the full-sample autocorrelations. If I use data after 1931 to estimate 1-year autocorrelations, the average estimate drops from -0.08 to 0.16. The autocorrelations are not as significant as the monthly regressions, since they miss reversals beyond 1-year, but the estimates are nearly as large as the 3- and 5-year autocorrelations in Table 2. I will argue later that the post-1931 sample provides a more accurate picture.

The patterns across size portfolios in Panel A are also interesting. Portfolios above the median market value of NYSE stocks have the most negative estimates. For portfolios $1-6$, the temporary component of returns varies from $2.1 \%$ to $34.7 \%$, with an average of $21.9 \%$. For portfolios $7-12$, the percentage varies from $34.7 \%$ to $44.9 \%$, with an average of $39.3 \%$. Reversals drop off slightly for the very largest firms, but they remain more negative than any of the estimates in the bottom size quartile. In addition, variation in conditional expected returns tends to be greater for the larger stocks. Forecasts of 18-month returns have a standard deviation of $8.5 \%$ for the smallest six portfolios and $10.2 \%$ for the largest six. These patterns, which run counter to conventional wisdom, are generally supported by the 
other holding periods.

Panels $\mathrm{B}$ and $\mathrm{C}$ report regressions using 3- and 5-year returns. The predictive power of 3-year returns is relatively weak, while the power of 5-year returns is comparable to 1-year returns. Using 3year returns, only a few of the individual months, and none of the joint tests, is significant at the $5 \%$ level. However, this probably overstates the drop in predictive power when going from 1- to 3-year returns. All but three of the estimates for portfolios $4-11$ are more than one standard error below zero. Exactly half of the estimates for these portfolios have p-values between 0.05 and 0.10 . In the last column, the 18month sums are significant at the $10 \%$ level for five portfolios. The estimates are, of course, highly correlated across portfolios, so it may not be surprising to find clustering of significance levels. But my point here is simply that the differences between 1- and 3-year returns are less dramatic than the statistical tests might suggest.

The results for 5-year returns, in Panel C, provide stronger evidence of reversals. In contrast to 1year returns, mean reversion is most pronounced at the early lags. The slope estimates are significant in months $1-10$ and remain negative for the following eight months. The average coefficient is greater than two standard errors below zero in months $3-8$. The largest estimates are close to three standard errors below zero and significant at better than the $1 \%$ level. Joint tests across all 18-months are significant for the equal-weighted index and seven of the 12 size portfolios.

Economically, the predictive power of 1-year and 5-year returns is similar. The raw point estimates for 5-year returns are smaller, but the implied variation in expected returns is about the same. The table shows that, on average, $10.1 \%$ of 5 -year returns reverse over the following 18-months. This compares with $30.9 \%$ for 1 -year returns. However, the average standard deviation of 1 -year returns is $37 \%$ while the standard deviation of 5-year returns is over 100\% during this time period. The higher volatility of 5year implies the variation in predicted returns is about the same (approximately $9.5 \%$ for the average portfolio)! 7

\footnotetext{
${ }^{7}$ It would be interesting to test whether 1- and 5-year returns have incremental explanatory power relative to each other. The evidence in Table 3 suggests they both are important: if only 1-year returns are significant, I would expect the 5-year slope estimates to be closer to zero. The 5-year regressions add four years to the predictive variable. If these years are simply noise, without predictive power, the slope coefficients in Panel C should drop by roughly 4/5ths compared with Panel A. The actual declines are smaller, between 1/2 and 2/3.
} 
Again, the predictive power of 5-year returns appears to be as strong for large stocks as for small stocks. The slope coefficients are greatest for portfolios $7-9$, consisting of firms in the 3rd size quartile. The estimates are significant for portfolios $3-9$ and they drop considerably in magnitude for the very smallest and largest portfolios. In contrast to 1-year returns, the estimates are fairly symmetric across size portfolios. Indeed, as a general rule, the data suggest that mean reversion in small stocks tends to catch up to that in large stocks as the holding period grows. Regressions for other sample periods and for 7year returns confirm this observation.

When interpreting the results, it is important to remember that estimates in adjacent months are highly correlated. The correlation is roughly equal to $(k-1) / k$, the overlap in consecutive observations of the predictive variable. For the 5-year regressions, the correlation between adjacent columns is approximately 0.96 (58 / 60 because each column is the sum of two months). The correlation is lower, 0.85 , for the 1-year regressions. This difference probably explains why the pattern across forecast horizons is smoother for 5-year returns. I note, however, that some of the changes from one month to the next in Panel C appear to be statistically significant. For example, the average coefficient drops by 0.45 between columns 1 and 2 and then jumps by about the same amount, 0.43 , between columns 5 and 6 . The standard deviation of these changes is approximately 0.20 , suggesting that the patterns are not simply random fluctuations in the data. (Recognizing, of course, that searching for the largest changes induces a data-snooping bias.)

\subsection{Monthly regressions, $1946-1998$}

The full-sample tests provide strong evidence of reversals. Previous studies, however, suggest that any trace of mean reversion disappear after 1940. That finding raises doubts about the reliability of the full-sample regressions: it is not clear whether the volatile Depression era simply provides a fertile testing ground or whether the patterns are unique to that period. Mean reversion after 1940 would go a long way to showing that the patterns are real.

Table 4 reports monthly regressions for the period 1946 - 1998. January 1946 is the first month that enters as a dependent variable in these regressions, so the predictive variables actually use returns from 
the early 1940s. The statistical significance is again based on the simulated distribution of White's (1980) t-statistics. These results may be excessively conservative: there is little evidence during this period that changes in volatility are correlated with past returns. The inferences below would be uniformly stronger if the tests are based on normal t-statistics.

Panel A shows that the predictive power of 1-year returns remains strong in this period. Moreover, the general patterns across forecast horizons and size portfolios are similar to those in the full sample. The slope estimates are, with one exception, everywhere negative for months $3-18$; most are more than one standard error below zero. The individual estimates, as well as the averages across the 12 size portfolios, are strongly significant in months $9-14$, with some significance earlier in months 7 and 8 . During those middle months, the p-value of the average coefficient ranges from 0.008 (months $11-12$ ) to 0.059 (months $7-8$ ). In addition, the three market indices are negatively autocorrelated, with significance levels between 0.005 and 0.024 in months $9-14$. The final column shows that significance carries over to the joint tests. Mean reversion across all months is significant for 8 of the 12 size portfolios and the three market indices.

Economically, the coefficients remain large, but smaller than the estimates from the full sample. Temporary price movements account for between $20 \%$ and $30 \%$ of annual returns for most portfolios (compared with $25 \%$ to $45 \%$ in the full sample). Portfolios in the 3rd quartile exhibit the strongest mean reversion, for which $29 \%$ to $31 \%$ of annual returns reverse over the following 18 months. The estimates for the smallest stocks once again trail off, but not as much as in the full sample. The estimate for portfolio 1 drops from $-2.1 \%$ in the full sample to $-18.3 \%$ after 1945 (neither is significant at conventional levels). Finally, it is clear from the table that mean reversion shows up in prices slowly. The largest estimates are for months $9-14$, and mean reversion in those months accounts for a substantial fraction of the reversals.

These results largely confirm the conclusions from the full sample. They also support Lewellen's (2000) evidence that momentum profits (Jegadeesh and Titman, 1993) do not translate into persistence in returns. Lewellen shows that size portfolios, similar to those used here, exhibit strong momentum over 6to 12-month horizons: a strategy that buys past winners and sells past losers earns significant profits for 
up to 18 months after formation. Despite this momentum, size portfolios are negatively autocorrelated over 6- and 12-month horizons. (The apparent contradiction is explained by cross-serial correlation among stocks.) Together with the results here, the evidence suggests that mean reversion exists at all but the very shortest horizons.

As an aside, it is interesting to compare the standard errors reported in Tables 3 and 4 . Even though the subsample regressions use 15 fewer years of data, the standard errors decline for all but the smallest stocks. The standard errors in Table 4 are also more uniform across portfolios. In principle, the standard errors should depend only on the length of the sample, and not on the portfolio, which seems nearly true after 1945. The standard errors should also be fairly uniform across monthly lags, but both Tables 3 and 4 show that the early lags tend to be less precise.

The regressions with 3- and 5-year returns, reported in Panels B and C, provide weaker evidence of mean reversion than 1-year returns. Compared to the full sample, however, the predictive power of 3 year returns actually increases after 1945. Panel B shows that many of the individual slope coefficients on 3-year returns are significantly negative. The average coefficient is significant in months $7-12$, and the return on the average size portfolio is negatively autocorrelated at lags of 7 to 14 months. More generally, most coefficients are between 1.25 and 2.00 standard errors below zero, with roughly half of the individual estimates significant at the $10 \%$ level. These results, however, imply only weak significance for the joint tests. Across all 18 months, 3-year returns have significant predictive power for only two portfolios, 7 and 9 . The p-values for portfolios 4 through 10 range from 0.032 to 0.086 , and the average size portfolio is significant at the 0.056 level. Taken as a whole, 3-year returns appear to be marginally significant.

In contrast, Panel $\mathrm{C}$ shows that the predictive power of 5-year returns largely disappears. Only a few of the individual coefficients, and none of the joint tests, is significant at the 5\% level. The slope estimates for the equal-weighted index and the average size portfolio are typically more than one standard error below zero, but the estimates for the value-weighted index are close to zero and even slightly positive. Over all 18 months, estimates for the smaller portfolios are roughly 1.2 standard errors below zero, with a minimum p-value of 0.072 for portfolio 3 . Compared with the full-sample evidence in Table 
2, the estimates drop by more than half. Thus, the predictive power of 5-year returns, if real, is too weak to show up reliably in the post-1945 period.

\subsection{Predictive power of 1-year returns in various subperiods}

The evidence above suggests that 1-year returns have strong predictive power. The reversals are statistically significant in both the full sample and the shorter post-1945 period. However, as noted above, the full-sample results are sensitive to the first few years of CRSP data. The reader might worry that the subperiod results are also sensitive to the period chosen, so it might be useful to look at the data a bit more closely.

Table 5 reports bias-adjusted slope coefficients when 12-month returns (Panel A) and 18-month returns (Panel B) are regressed on lagged annual returns. The 12-month regressions are standard autocorrelations and the 18-month regressions mimic the tests in Tables 3 and 4 (the slopes are similar to the 18-month sums in those tables). I report estimates for three subperiods, 1932 - 1945, 1946 - 1971, and 1972 - 1998. The first period covers the Depression and World War II years; the other two periods split the post-1945 sample roughly in half.

The table shows that mean reversion in 1-year returns is quite robust. The point estimates for the three subperiods are all negative, similar in magnitude, and typically at least one standard error below zero. Reversals appear to be strongest in the second subsample, 1946 - 1971, but the difference between that period and the others is well within the bounds of sampling variation.

Since the three periods are fairly short, it is not surprising that the statistical significance in each is modest. However, weak significance in all three periods translates into strong joint significance. For example, the average autocorrelation in Panel A has a p-value of 0.161 in the first subperiod, 0.120 in the second, and 0.298 in the third. The estimates are essentially independent, so the probability that we would observe autocorrelations this negative is less than $0.6 \%$ if the true autocorrelation is zero $(0.161 \times$ $0.120 \times 0.298$ ). Similarly, the probability of observing the 18 -month slope estimates is less than $0.3 \%$ $(0.137 \times 0.082 \times 0.303)$. In fact, the estimates are significant when any two subperiods are considered together. The consistency of the estimates provides strong evidence that the true autocorrelations are 
negative.

Finally, I note that the estimates are similar for other subperiods (not reported in the table). For example, the average 18 -month slope is -0.21 for the period $1941-1998,-0.31$ for the period $1951-$ 1998, and -0.27 for the period $1961-1998$ (these have not been corrected for bias, which should be between -0.04 and -0.06 extrapolating from the other periods). The individual slope coefficients are also similar to those reported in Tables $2-6$. Overall, mean reversion in annual returns seems to be reliably present in the data.

\section{Summary}

At the beginning of the paper, I described four stylized facts taken from the literature on longhorizon autocorrelations in returns. They provide a convenient framework for discussing the contributions of the current study.

(a) Mean reversion in stock prices is marginally significant, at best. No. Long-horizon autocorrelations may be marginally significant, but the evidence for mean reversion is strong. The monthly regressions show that 1 -year and 5 -year returns both have significant predictive power in the full sample (1926 - 1998). For most size portfolios and the three market indices, between $25 \%$ and $45 \%$ of annual returns reverse over the subsequent 18 months. The percentage falls to between $10 \%$ and $15 \%$ for 5-year returns.

(b) Mean reversion is non-existent after 1945. No. The predictive power of past returns appears to fall after 1945, but there remains reliable evidence of reversals. One-year returns, and to a less extent 3year returns, are negatively correlated with future returns for at least 14 months. Between $20 \%$ and $30 \%$ of annual returns reverse over the subsequent 18 months. The reversals are statistically significant 8 of the 12 size portfolios and for all three market indices. The point estimates imply economically significant time-variation in expected returns.

(c) Mean reversion is stronger for small stocks. No. The monthly regressions consistently find that 
mean reversion is as strong or stronger for larger portfolios. Size portfolios above the median market value of NYSE stocks typically have the most negative point estimates, especially the portfolios in the 3 rd quartile. Across the size portfolios, mean reversion appears to drop off for both the very smallest and the very largest portfolios.

(d) Mean reversion is strongest over 3-to 5-year horizons. No. From a statistical standpoint, 1-year returns have the most reliable predictive power. They are negatively related to future returns in both the full sample, the shorter 1946 - 1998 period, and various subperiods. Five-year returns are strongly significant in the full sample, but not in the shorter subperiod; three-year returns are marginally significant only after 1945 . Economically, the predictive power of 1-year returns is also as strong or stronger than 3-and 5-year returns. In the full sample, 1- and 5-year returns forecast similar time-variation in expected returns. After 1945, the predictive power of 1-year returns is stronger than either of the other holding periods.

This paper has not attempted to disentangle rational- and irrational-pricing stories for mean reversion. Time variation in expected returns appears to be economically large, but perhaps not impossible for rational models to explain. A number of tests could help distinguish among potential theories. For example, one might test whether expected stock returns are always greater than the riskfree rate - negative risk premia are difficult to reconcile with market efficiency. Also, if mean reversion captures changes in discount rates, then we might expect that the patterns in the data are related to business conditions or changes in risk. Finally, the patterns across size portfolios and time horizons provide a rich source of information. A model should explain why mean reversion is strongest in 1-year returns, why reversals take many months to show up in prices, and why reversals appear weak in the very smallest and very largest portfolios. 


\section{References}

Campbell, John and Ludger Hentschel, 1992, No news is good news: An asymmetric model of changing volatility in stock returns, Journal of Financial Economics 31, 281-318.

Fama, Eugene and Kenneth French, 1988. Permanent and temporary components of stock prices. Journal of Political Economy 96, 246-273.

Jegadeesh, Narasimhan, 1990. Seasonality in stock price mean reversion: Evidence from the U.S. and the U.K. Journal of Finance 46, 1427 - 1444.

Jegadeesh, Narasimhan and Sheridan Titman, 1993, Returns to buying winners and selling losers: Implications for stock market efficiency, Journal of Finance 48, 65-91.

Kendall, Maurice, 1953. The analysis of economic time series, part I: Prices. Journal of the Royal Statistical Society 96, 11-25.

Kendall, Maurice, 1954. Note on bias in the estimation of autocorrelation. Biometrika 41, 403-404.

Kim, Myung, Charles Nelson, and Richard Startz, 1991. Mean reversion in stock prices? A reappraisal of the empirical evidence. Review of Economic Studies 58, 515-528.

Lee, Charles, Andrei Shleifer, and Richard Thaler, 1991, Investor sentiment and the closed-end fund puzzle, Journal of Finance 46, 75-109.

Lewellen, Jonathan, 2000, Momentum profits and the autocorrelation of stock returns, Working paper (Massachusetts Institute of Technology, Cambridge, MA).

Lo, Andrew and A. Craig MacKinlay, 1990, When are contrarian profits due to stock market overreaction?, Review of Financial Studies 3, 175-205.

Marriott, F.H.C. and J.A. Pope, 1954. Bias in the estimation of autocorrelations. Biometrika 41, 390-402.

Newey, Whitney and Kenneth West, 1987, A simple, positive semi-definite, heteroskedasticity and autocorrelation consistent covariance matrix, Econometrica 55, 703-708.

Poterba, James and Lawrence Summers, 1988. Mean reversion in stock prices: Evidence and implications. Journal of Financial Economics 22, 27-59.

Richardson, Matthew, 1993. Temporary components of stock prices: A skeptic's view. Journal of Business and Economic Statistics 11, 199-207.

Richardson, Matthew and James Stock, 1989. Drawing inferences from statistics based on multiyear asset returns. Journal of Financial Economics 25, 323-348.

Stambaugh, Robert, 1999. Predictive regressions. Journal of Financial Economics 54, 375-421.

White, Halbert, 1980, A heteroskedasticity-consistent covariance matrix estimator and a direct test for heteroskedasticity, Econometrica 48, 817-838.

White, Halbert, 1984, Asymptotic theory for econometricians (Academic Press, Orlando, FL). 
Table 1

Summary statistics, $1926-1998$

Each month from January 1926 through December 1998, 12 value-weighted size portfolios are formed from all NYSE, Amex, and NASDAQ stocks classified as ordinary common equity on CRSP. The breakpoints are determined by equally-spaced NYSE percentiles. The table reports the average return and standard deviation of each portfolio (in percent), the number of firms in the portfolio on average and at the end of the sample, and the fraction of total market value in the portfolio on average and at the end of the sample. The table also reports these statistics for equal- and value-weighted market indices and the equal-weighted combination of the 12 size portfolios.

\begin{tabular}{|c|c|c|c|c|c|c|c|c|c|c|}
\hline \multirow[b]{2}{*}{ Portfolio } & \multicolumn{2}{|c|}{ Average return $(\%)$} & \multicolumn{2}{|c|}{ Std. deviation (\%) } & \multicolumn{3}{|c|}{ Avg. number of firms } & \multicolumn{3}{|c|}{ Avg. market value (\%) } \\
\hline & $1926-98$ & 1946-98 & 1926-98 & 1946-98 & 1926-98 & 1946-98 & $12 / 98$ & 1926-98 & 1946-98 & $12 / 98$ \\
\hline Small & 1.87 & 1.22 & 11.71 & 6.08 & 1,074 & 1,432 & 3,141 & 0.8 & 1.1 & 0.7 \\
\hline 2 & 1.46 & 1.21 & 9.96 & 5.64 & 275 & 352 & 908 & 0.8 & 1.0 & 0.7 \\
\hline 3 & 1.24 & 1.17 & 8.86 & 5.58 & 207 & 260 & 607 & 1.0 & 1.1 & 0.8 \\
\hline 4 & 1.22 & 1.19 & 8.41 & 5.43 & 177 & 219 & 505 & 1.2 & 1.4 & 1.0 \\
\hline 5 & 1.27 & 1.23 & 7.79 & 5.24 & 157 & 193 & 427 & 1.6 & 1.8 & 1.2 \\
\hline 6 & 1.23 & 1.21 & 7.49 & 5.11 & 142 & 173 & 370 & 2.1 & 2.3 & 1.4 \\
\hline 7 & 1.20 & 1.18 & 7.17 & 5.01 & 127 & 152 & 354 & 2.7 & 2.9 & 2.0 \\
\hline 8 & 1.10 & 1.16 & 6.80 & 4.82 & 119 & 141 & 330 & 3.6 & 3.9 & 2.7 \\
\hline 9 & 1.14 & 1.15 & 6.59 & 4.77 & 114 & 134 & 279 & 5.2 & 5.5 & 3.7 \\
\hline 10 & 1.09 & 1.17 & 6.29 & 4.52 & 108 & 126 & 253 & 8.1 & 8.3 & 6.0 \\
\hline 11 & 1.03 & 1.10 & 5.83 & 4.31 & 103 & 120 & 233 & 14.2 & 13.8 & 11.7 \\
\hline Largest & 0.97 & 1.06 & 5.19 & 4.00 & 101 & 117 & 221 & 58.7 & 56.9 & 68.1 \\
\hline VW index & 1.01 & 1.10 & 5.50 & 4.15 & 2,706 & 3,420 & 7,628 & 100.0 & 100.0 & 100.0 \\
\hline EW index & 1.30 & 1.23 & 7.55 & 5.17 & 2,706 & 3,420 & 7,628 & 100.0 & 100.0 & 100.0 \\
\hline Avg. size portfolio ${ }^{a}$ & 1.24 & 1.17 & 7.36 & 4.85 & 2,706 & 3,420 & 7,628 & 100.0 & 100.0 & 100.0 \\
\hline
\end{tabular}

\footnotetext{
${ }^{a}$ Equal-weighted combination of the 12 size portfolios.
} 
Table 2

Full autocorrelations

The table reports bias-adjusted autocorrelations and Newey-West (1987) standard errors for 1-, 3-, and 5-year returns. Panel A shows estimates for 1926 - 1998 and Panel B shows estimates for 1946 - 1998. The table reports autocorrelations for 12 size portfolios, equal- and value-weighted market indices, and the equalweighted combination of the size portfolios. 'Average $\rho$ ' equals the average autocorrelation for the 12 size portfolios. The coefficients are estimated from OLS regressions using overlapping monthly observations, and bias and significance levels are obtained from bootstrap simulations.

\begin{tabular}{|c|c|c|c|c|c|c|}
\hline \multirow[b]{2}{*}{ Portfolio } & \multicolumn{3}{|c|}{ Autocorrelation } & \multicolumn{3}{|c|}{ Std error } \\
\hline & $1 \mathrm{yr}$ & $3 \mathrm{yr}$ & $5 \mathrm{yr}$ & $1 \mathrm{yr}$ & $3 \mathrm{yr}$ & $5 \mathrm{yr}$ \\
\hline \multicolumn{7}{|c|}{ Panel A: 1926 - 1998} \\
\hline Small & 0.01 & -0.05 & -0.05 & 0.05 & 0.09 & 0.08 \\
\hline 2 & -0.02 & -0.16 & -0.17 & 0.06 & 0.13 & 0.14 \\
\hline 3 & -0.07 & -0.22 & -0.30 & 0.08 & 0.12 & 0.13 \\
\hline 4 & -0.09 & -0.25 & $-0.32 *$ & 0.09 & 0.13 & 0.13 \\
\hline 5 & -0.11 & -0.23 & $-0.29 *$ & 0.10 & 0.11 & 0.10 \\
\hline 6 & -0.09 & -0.26 & $-0.31 *$ & 0.10 & 0.11 & 0.12 \\
\hline 7 & -0.13 & $-0.27 *$ & $-0.26 *$ & 0.11 & 0.10 & 0.10 \\
\hline 8 & -0.11 & -0.21 & -0.12 & 0.12 & 0.11 & 0.10 \\
\hline 9 & -0.13 & -0.31 & -0.25 & 0.11 & 0.13 & 0.11 \\
\hline 10 & -0.12 & -0.23 & -0.06 & 0.12 & 0.10 & 0.09 \\
\hline 11 & -0.08 & -0.26 & -0.09 & 0.12 & 0.12 & 0.12 \\
\hline Large & -0.01 & -0.18 & 0.13 & 0.12 & 0.13 & 0.09 \\
\hline VW index & -0.07 & -0.22 & 0.00 & 0.12 & 0.12 & 0.09 \\
\hline EW index & -0.08 & -0.24 & $-0.34 *$ & 0.09 & 0.12 & 0.13 \\
\hline Ave. size portfolio & -0.10 & -0.27 & -0.27 & 0.09 & 0.13 & 0.15 \\
\hline Average $\rho$ & -0.08 & -0.22 & -0.17 & 0.09 & 0.09 & 0.09 \\
\hline \multicolumn{7}{|c|}{ Panel B: 1946 - 1998} \\
\hline Small & -0.09 & -0.05 & 0.05 & 0.10 & 0.10 & 0.05 \\
\hline 2 & -0.13 & -0.06 & -0.10 & 0.10 & 0.14 & 0.10 \\
\hline 3 & -0.16 & -0.12 & -0.12 & 0.10 & 0.15 & 0.11 \\
\hline 4 & -0.18 & -0.08 & -0.17 & 0.10 & 0.16 & 0.11 \\
\hline 5 & -0.18 & -0.06 & -0.12 & 0.10 & 0.17 & 0.12 \\
\hline 6 & -0.21 & -0.09 & -0.15 & 0.10 & 0.15 & 0.12 \\
\hline 7 & $-0.23 *$ & -0.10 & -0.10 & 0.11 & 0.15 & 0.09 \\
\hline 8 & -0.22 & -0.02 & -0.02 & 0.10 & 0.18 & 0.13 \\
\hline 9 & $-0.26 *$ & -0.06 & 0.08 & 0.10 & 0.15 & 0.13 \\
\hline 10 & -0.21 & 0.00 & 0.07 & 0.11 & 0.15 & 0.14 \\
\hline 11 & -0.21 & 0.08 & 0.28 & 0.10 & 0.15 & 0.16 \\
\hline Large & -0.07 & 0.14 & 0.30 & 0.10 & 0.14 & 0.17 \\
\hline VW index & -0.18 & 0.08 & 0.20 & 0.10 & 0.15 & 0.16 \\
\hline EW index & -0.16 & -0.04 & -0.20 & 0.10 & 0.18 & 0.15 \\
\hline Ave. size portfolio & -0.21 & -0.10 & -0.07 & 0.10 & 0.15 & 0.09 \\
\hline Average $\rho$ & -0.18 & -0.03 & 0.00 & 0.09 & 0.13 & 0.08 \\
\hline
\end{tabular}

\footnotetext{
* Estimate is significant at the $5 \%$ level (one-sided) based on bootstrap simulations.
} 
Table 3

Monthly regressions, 1926 - 1998

The table reports bias-adjusted slope coefficients and White (1980) standard errors when monthly returns are regressed on past 1-, 3-, or 5-year returns (Panels A, B, and C, respectively). The table shows estimates for horizons of 1 to 18 months (estimates for adjacent months are summed, i.e., $1+2,3+4, \ldots$ ) and the total across all months. Estimates are shown for 12 size portfolios, equal- and value-weighted market indices, and the equal-weighted combination of the 12 size portfolios. The coefficients are estimated from OLS regressions, and the bias and significance levels are obtained from bootstrap simulations.

\begin{tabular}{|c|c|c|c|c|c|c|c|c|c|c|}
\hline \multirow[b]{2}{*}{ Portfolio } & \multicolumn{10}{|c|}{ Forecast horizon (months) } \\
\hline & $1-2$ & $3-4$ & $5-6$ & $7-8$ & $9-10$ & $11-12$ & $13-14$ & $15-16$ & $17-18$ & Sum \\
\hline \multicolumn{11}{|c|}{ Panel A: Lagged 1-year returns } \\
\hline & \multicolumn{10}{|c|}{$\beta \times 100$} \\
\hline Small & 1.9 & -1.1 & 0.5 & 2.4 & 0.0 & $-2.3^{*}$ & $-2.2 *$ & -1.0 & -0.3 & -2.1 \\
\hline 2 & 1.0 & $-2.7 *$ & -0.4 & 2.1 & -1.0 & $-3.7 *$ & $-3.3 *$ & -1.8 & -1.0 & -10.8 \\
\hline 3 & -0.7 & $-4.9 *$ & -2.2 & 0.8 & -2.8 & $-5.8 *$ & $-4.8^{*}$ & -2.2 & -1.7 & -24.4 \\
\hline 4 & -0.7 & $-4.7 *$ & -2.4 & 0.3 & -3.0 & $-6.0^{*}$ & $-5.4 *$ & -2.7 & -1.7 & -26.4 \\
\hline 5 & -2.0 & $-5.9 *$ & -3.4 & -0.6 & $-4.0 *$ & $-6.8 *$ & $-6.3 *$ & -3.3 & -2.6 & $-34.7 *$ \\
\hline 6 & -2.2 & $-5.6 *$ & -3.2 & -0.8 & $-3.8 *$ & $-6.5 *$ & $-5.6^{*}$ & -2.9 & -2.4 & -33.1 \\
\hline 7 & -2.3 & $-5.7 *$ & -3.8 & -1.7 & $-5.3^{*}$ & $-7.4^{*}$ & $-6.3^{*}$ & -3.7 & -3.1 & -39.5 \\
\hline 8 & -3.1 & $-6.6^{*}$ & $-4.6^{*}$ & -2.6 & $-5.3 *$ & $-7.5^{*}$ & $-6.3 *$ & -3.4 & -2.6 & -42.0 \\
\hline 9 & -2.5 & $-5.5^{*}$ & -3.9 & -2.2 & $-4.9 *$ & $-6.4^{*}$ & $-5.4^{*}$ & -2.9 & -2.3 & -36.2 \\
\hline 10 & -4.4 & $-6.5^{*}$ & $-4.9 *$ & -3.2 & $-5.8 *$ & $-7.2 *$ & $-6.2 *$ & -3.6 & -3.1 & $-44.9 *$ \\
\hline 11 & -2.9 & $-4.7 *$ & -4.0 & -3.4 & $-5.5 *$ & $-6.6^{*}$ & $-5.3 *$ & -3.4 & -2.7 & -38.6 \\
\hline Large & -2.2 & -3.6 & -3.1 & -2.7 & $-5.2 *$ & $-6.2 *$ & $-5.4^{*}$ & -3.4 & -2.8 & -34.7 \\
\hline VW index & -3.1 & $-5.1 *$ & -4.0 & -3.3 & $-5.8 *$ & $-7.0 *$ & $-5.9 *$ & -3.6 & -3.0 & $-40.9:$ \\
\hline EW index & -0.6 & $-4.3^{*}$ & -2.5 & -0.4 & $-3.5^{*}$ & $-5.9 *$ & $-5.3 *$ & -3.0 & -2.3 & -27.8 \\
\hline Ave. size port & -1.0 & $-4.6^{*}$ & -2.4 & -0.2 & $-3.4^{*}$ & $-5.9 *$ & $-5.1 *$ & -2.8 & -2.1 & $-27.7^{*}$ \\
\hline \multirow[t]{2}{*}{ Average $\beta$} & -1.7 & $-4.8^{*}$ & -3.0 & -1.0 & $-4.0 *$ & $-6.1 *$ & $-5.3 *$ & -2.9 & -2.2 & $-30.9 *$ \\
\hline & \multicolumn{10}{|c|}{ std error $\times 100$} \\
\hline Small & 1.5 & 1.0 & 1.4 & 2.0 & 0.8 & 0.8 & 1.1 & 0.9 & 1.0 & 7.3 \\
\hline 2 & 1.8 & 1.4 & 1.7 & 2.2 & 1.3 & 1.4 & 1.6 & 1.4 & 1.7 & 9.9 \\
\hline 3 & 2.1 & 2.0 & 2.3 & 2.8 & 1.8 & 2.0 & 2.4 & 2.1 & 2.1 & 14.5 \\
\hline 4 & 2.1 & 2.0 & 2.4 & 3.0 & 1.9 & 2.1 & 2.4 & 2.1 & 2.3 & 14.9 \\
\hline 5 & 2.5 & 2.4 & 2.4 & 2.8 & 2.2 & 2.3 & 2.6 & 2.4 & 2.5 & 16.8 \\
\hline 6 & 2.7 & 2.4 & 2.5 & 2.8 & 2.2 & 2.3 & 2.6 & 2.4 & 2.5 & 16.7 \\
\hline 7 & 2.8 & 2.6 & 2.6 & 3.0 & 2.2 & 2.4 & 2.6 & 2.4 & 2.4 & 17.0 \\
\hline 8 & 2.9 & 2.8 & 2.7 & 2.8 & 2.5 & 2.5 & 2.7 & 2.5 & 2.6 & 18.9 \\
\hline 9 & 2.7 & 2.5 & 2.6 & 2.6 & 2.3 & 2.3 & 2.4 & 2.3 & 2.3 & 16.6 \\
\hline 10 & 3.5 & 3.1 & 2.9 & 2.9 & 2.8 & 2.8 & 2.9 & 2.8 & 2.7 & 21.3 \\
\hline 11 & 3.0 & 2.8 & 2.7 & 2.6 & 2.6 & 2.6 & 2.7 & 2.6 & 2.5 & 19.7 \\
\hline Large & 3.2 & 3.0 & 2.8 & 2.6 & 2.7 & 2.7 & 2.7 & 2.6 & 2.4 & 20.7 \\
\hline VW index & 3.1 & 2.9 & 2.8 & 2.6 & 2.6 & 2.7 & 2.7 & 2.6 & 2.5 & 20.2 \\
\hline EW index & 2.3 & 2.0 & 2.1 & 2.5 & 1.8 & 1.9 & 2.2 & 2.0 & 2.1 & 14.1 \\
\hline Ave. size port & 2.3 & 2.0 & 2.2 & 2.6 & 1.8 & 2.0 & 2.2 & 2.0 & 2.1 & 14.1 \\
\hline Average $\beta$ & 2.4 & 2.2 & 2.2 & 2.5 & 2.0 & 2.1 & 2.3 & 2.1 & 2.1 & 15.3 \\
\hline
\end{tabular}

* Estimate is significant at the 5\% level (one-sided) based on bootstrap simulations. 
Table 3

Monthly regressions, 1926 - 1998 (continued)

\begin{tabular}{|c|c|c|c|c|c|c|c|c|c|c|}
\hline \multirow[b]{2}{*}{ Portfolio } & \multicolumn{10}{|c|}{ Forecast horizon (months) } \\
\hline & $1-2$ & $3-4$ & $5-6$ & $7-8$ & $9-10$ & $11-12$ & $13-14$ & $15-16$ & $17-18$ & Sum \\
\hline \multicolumn{11}{|c|}{ Panel B: Lagged 3-year returns } \\
\hline & \multicolumn{10}{|c|}{$\beta \times 100$} \\
\hline Small & 0.5 & 0.3 & 0.6 & 0.8 & 0.6 & 0.5 & 0.1 & -0.1 & -0.1 & 3.2 \\
\hline 2 & 0.0 & -0.2 & 0.1 & 0.4 & 0.1 & -0.1 & -0.6 & -0.7 & -0.9 & -1.8 \\
\hline 3 & -0.8 & -1.0 & -0.9 & -0.7 & -1.2 & -1.3 & -1.6 & -1.6 & -1.8 & -10.9 \\
\hline 4 & -1.0 & -1.2 & -1.1 & -0.9 & -1.3 & -1.7 & $-2.0 *$ & -1.7 & -1.9 & -12.7 \\
\hline 5 & -1.7 & -1.8 & -1.5 & -1.4 & -1.6 & -1.7 & -1.9 & -1.6 & -1.7 & -14.9 \\
\hline 6 & -1.7 & -1.7 & -1.8 & -1.6 & -1.8 & -1.7 & -1.9 & -1.5 & -1.7 & -15.3 \\
\hline 7 & -1.9 & -2.1 & -2.0 & -1.8 & -2.2 & -2.3 & $-2.3^{*}$ & -1.8 & -1.9 & -18.4 \\
\hline 8 & -2.5 & -2.4 & -2.3 & -2.3 & -2.6 & -2.5 & $-2.4^{*}$ & -1.7 & -1.7 & -20.4 \\
\hline 9 & -2.2 & -2.3 & -2.1 & -2.0 & -2.3 & -2.1 & -2.1 & -1.7 & -1.5 & -18.5 \\
\hline 10 & -3.3 & -3.0 & -2.7 & -2.5 & -2.8 & -2.6 & -2.4 & -1.7 & -1.5 & -22.4 \\
\hline 11 & -1.6 & -1.5 & -1.5 & -1.6 & -2.0 & -1.9 & -1.9 & -1.4 & -1.2 & -14.7 \\
\hline Large & -1.4 & -1.1 & -1.3 & -1.3 & -1.6 & -1.4 & -1.4 & -0.8 & -0.5 & -10.7 \\
\hline VW index & -2.1 & -1.9 & -1.9 & -1.9 & -2.2 & -2.1 & -2.0 & -1.3 & -1.1 & -16.5 \\
\hline EW index & -1.0 & -1.2 & -1.0 & -0.9 & -1.3 & -1.4 & -1.6 & -1.4 & -1.5 & -11.2 \\
\hline Ave. size port & -1.1 & -1.2 & -0.9 & -0.7 & -1.1 & -1.3 & -1.5 & -1.4 & -1.4 & -10.6 \\
\hline \multirow[t]{2}{*}{ Average $\beta$} & -1.5 & -1.5 & -1.4 & -1.2 & -1.5 & -1.6 & -1.7 & -1.4 & -1.4 & -13.1 \\
\hline & \multicolumn{10}{|c|}{ std error $\times 100$} \\
\hline Small & 0.5 & 0.4 & 0.4 & 0.4 & 0.4 & 0.5 & 0.4 & 0.4 & 0.4 & 3.6 \\
\hline 2 & 0.8 & 0.8 & 0.8 & 0.8 & 0.8 & 0.8 & 0.8 & 0.7 & 0.8 & 6.4 \\
\hline 3 & 1.2 & 1.1 & 1.1 & 1.1 & 1.1 & 1.1 & 1.1 & 1.1 & 1.1 & 9.4 \\
\hline 4 & 1.3 & 1.2 & 1.2 & 1.2 & 1.2 & 1.2 & 1.1 & 1.1 & 1.2 & 10.1 \\
\hline 5 & 1.4 & 1.4 & 1.4 & 1.4 & 1.4 & 1.4 & 1.3 & 1.3 & 1.3 & 11.6 \\
\hline 6 & 1.4 & 1.4 & 1.3 & 1.4 & 1.4 & 1.3 & 1.2 & 1.3 & 1.3 & 11.2 \\
\hline 7 & 1.5 & 1.5 & 1.5 & 1.5 & 1.5 & 1.4 & 1.3 & 1.3 & 1.3 & 12.1 \\
\hline 8 & 1.7 & 1.7 & 1.6 & 1.6 & 1.6 & 1.5 & 1.4 & 1.4 & 1.4 & 13.2 \\
\hline 9 & 1.5 & 1.5 & 1.5 & 1.4 & 1.4 & 1.4 & 1.3 & 1.3 & 1.3 & 11.8 \\
\hline 10 & 2.0 & 1.9 & 1.9 & 1.8 & 1.8 & 1.7 & 1.6 & 1.6 & 1.5 & 15.1 \\
\hline 11 & 1.6 & 1.5 & 1.5 & 1.5 & 1.4 & 1.3 & 1.3 & 1.3 & 1.2 & 11.9 \\
\hline Large & 1.6 & 1.5 & 1.5 & 1.5 & 1.4 & 1.4 & 1.3 & 1.3 & 1.2 & 11.9 \\
\hline VW index & 1.7 & 1.6 & 1.6 & 1.6 & 1.5 & 1.5 & 1.4 & 1.4 & 1.3 & 12.8 \\
\hline EW index & 1.2 & 1.1 & 1.1 & 1.1 & 1.1 & 1.1 & 1.0 & 1.1 & 1.1 & 9.4 \\
\hline Ave. size port & 1.2 & 1.1 & 1.1 & 1.1 & 1.1 & 1.1 & 1.0 & 1.0 & 1.1 & 9.2 \\
\hline Average $\beta$ & 1.3 & 1.3 & 1.2 & 1.2 & 1.2 & 1.2 & 1.1 & 1.1 & 1.1 & 10.1 \\
\hline
\end{tabular}

* Estimate is significant at the $5 \%$ level (one-sided) based on bootstrap simulations. 
Table 3

Monthly regressions, 1926 - 1998 (continued)

\begin{tabular}{|c|c|c|c|c|c|c|c|c|c|c|}
\hline \multirow[b]{2}{*}{ Portfolio } & \multicolumn{10}{|c|}{ Forecast horizon (months) } \\
\hline & $1-2$ & $3-4$ & $5-6$ & $7-8$ & $9-10$ & $11-12$ & $13-14$ & $15-16$ & $17-18$ & Sum \\
\hline \multicolumn{11}{|c|}{ Panel C: Lagged 5-year returns } \\
\hline & \multicolumn{10}{|c|}{$\beta \times 100$} \\
\hline Small & 0.1 & $-0.1 *$ & $-0.1 *$ & $-0.1 *$ & -0.1 & 0.0 & 0.0 & 0.0 & 0.0 & -0.3 \\
\hline 2 & -0.2 & $-0.5^{*}$ & $-0.7 *$ & $-0.6^{*}$ & -0.6 & -0.4 & -0.2 & -0.3 & -0.3 & -3.8 \\
\hline 3 & $-1.1 *$ & $-1.6^{*}$ & $-1.6^{*}$ & $-1.5^{*}$ & $-1.5^{*}$ & -1.2 & -0.9 & -0.9 & -0.8 & $-11.2 *$ \\
\hline 4 & $-1.4 *$ & $-1.9 *$ & $-1.9 *$ & $-1.7 *$ & $-1.6^{*}$ & -1.1 & -0.9 & -0.8 & -0.7 & $-12.0 *$ \\
\hline 5 & $-1.4 *$ & $-1.9 *$ & $-1.9 *$ & $-1.7 *$ & $-1.6^{*}$ & -1.2 & -0.9 & -0.8 & -0.7 & $-12.3 *$ \\
\hline 6 & $-1.4^{*}$ & $-2.0 *$ & $-2.0 *$ & $-1.8^{*}$ & $-1.8 *$ & -1.2 & -0.9 & -0.7 & -0.6 & $-12.5 *$ \\
\hline 7 & $-1.9 *$ & $-2.5^{*}$ & $-2.4 *$ & $-2.0^{*}$ & $-1.9 *$ & -1.3 & -0.9 & -0.9 & -0.7 & $-14.5 *$ \\
\hline 8 & $-1.9 *$ & $-2.4^{*}$ & $-2.2 *$ & $-1.9^{*}$ & $-1.8^{*}$ & -1.3 & -0.9 & -0.8 & -0.6 & $-13.9 *$ \\
\hline 9 & $-1.9 *$ & $-2.4 *$ & $-2.3 *$ & $-1.9 *$ & -1.8 & -1.2 & -0.8 & -0.7 & -0.5 & $-13.5 *$ \\
\hline 10 & $-1.9 *$ & $-2.4^{*}$ & $-2.1^{*}$ & $-1.8^{*}$ & -1.7 & -1.2 & -0.8 & -0.7 & -0.5 & -13.2 \\
\hline 11 & $-1.5^{*}$ & $-1.9 *$ & $-1.8 *$ & $-1.6^{*}$ & -1.5 & -1.0 & -0.7 & -0.6 & -0.3 & -10.9 \\
\hline Large & -0.8 & -1.1 & -1.0 & -0.8 & -0.7 & -0.3 & -0.1 & -0.1 & 0.1 & -4.7 \\
\hline VW index & -1.5 & $-1.8 *$ & $-1.7 *$ & -1.4 & -1.3 & -0.8 & -0.6 & -0.5 & -0.2 & -9.8 \\
\hline EW index & $-1.1 *$ & $-1.6^{*}$ & $-1.6 *$ & $-1.5^{*}$ & $-1.4^{*}$ & -1.1 & -0.8 & -0.8 & -0.7 & $-10.4 *$ \\
\hline Ave. size port & $-0.8 *$ & $-1.3^{*}$ & $-1.4 *$ & $-1.3^{*}$ & $-1.2 *$ & -0.9 & -0.5 & -0.5 & -0.4 & $-8.3 *$ \\
\hline \multirow[t]{2}{*}{ Average $\beta$} & $-1.2 *$ & $-1.7^{*}$ & $-1.7 *$ & $-1.4^{*}$ & -1.4 & -1.0 & -0.7 & -0.6 & -0.5 & $-10.1 *$ \\
\hline & \multicolumn{10}{|c|}{ std error $\times 100$} \\
\hline Small & 0.1 & 0.1 & 0.1 & 0.1 & 0.2 & 0.2 & 0.2 & 0.2 & 0.2 & 1.3 \\
\hline 2 & 0.3 & 0.3 & 0.3 & 0.3 & 0.4 & 0.5 & 0.5 & 0.5 & 0.4 & 3.1 \\
\hline 3 & 0.6 & 0.7 & 0.6 & 0.7 & 0.8 & 0.8 & 0.8 & 0.7 & 0.7 & 5.7 \\
\hline 4 & 0.7 & 0.7 & 0.7 & 0.7 & 0.9 & 1.0 & 1.0 & 0.8 & 0.8 & 6.5 \\
\hline 5 & 0.8 & 0.8 & 0.7 & 0.8 & 0.9 & 1.0 & 1.0 & 0.8 & 0.7 & 6.6 \\
\hline 6 & 0.7 & 0.7 & 0.7 & 0.8 & 0.9 & 1.0 & 1.0 & 0.9 & 0.8 & 6.8 \\
\hline 7 & 0.9 & 0.9 & 0.8 & 0.9 & 1.0 & 1.1 & 1.1 & 0.9 & 0.8 & 7.4 \\
\hline 8 & 0.9 & 0.9 & 0.9 & 0.9 & 1.0 & 1.0 & 1.0 & 0.8 & 0.7 & 7.5 \\
\hline 9 & 0.9 & 0.9 & 0.8 & 0.9 & 1.1 & 1.2 & 1.1 & 0.9 & 0.8 & 7.7 \\
\hline 10 & 1.1 & 1.1 & 1.0 & 1.0 & 1.1 & 1.1 & 1.0 & 0.9 & 0.8 & 8.3 \\
\hline 11 & 0.9 & 0.9 & 0.8 & 0.9 & 1.0 & 1.0 & 0.9 & 0.8 & 0.7 & 7.1 \\
\hline Large & 0.9 & 0.9 & 0.8 & 0.8 & 0.9 & 0.8 & 0.8 & 0.7 & 0.6 & 6.6 \\
\hline VW index & 1.0 & 1.0 & 0.9 & 0.9 & 1.0 & 1.0 & 0.9 & 0.8 & 0.7 & 7.3 \\
\hline EW index & 0.6 & 0.6 & 0.6 & 0.6 & 0.7 & 0.8 & 0.8 & 0.7 & 0.6 & 5.4 \\
\hline Ave. size port & 0.5 & 0.5 & 0.5 & 0.5 & 0.7 & 0.8 & 0.8 & 0.7 & 0.6 & 4.9 \\
\hline Average $\beta$ & 0.7 & 0.7 & 0.7 & 0.7 & 0.8 & 0.9 & 0.8 & 0.7 & 0.6 & 5.8 \\
\hline
\end{tabular}

* Estimate is significant at the $5 \%$ level (one-sided) based on bootstrap simulations. 
Table 4

Monthly regressions, 1946 - 1998

The table reports bias-adjusted slope coefficients and White (1980) standard errors when monthly returns are regressed on past 1-, 3-, or 5-year returns (Panels A, B, and C, respectively). The table shows estimates for horizons of 1 to 18 months (estimates for adjacent months are summed, i.e., $1+2,3+4, \ldots$ ) and the total across all months. Estimates are shown for 12 size portfolios, equal- and value-weighted market indices, and the equal-weighted combination of the 12 size portfolios. The coefficients are estimated from OLS regressions, and the bias and significance levels are obtained from bootstrap simulations.

\begin{tabular}{|c|c|c|c|c|c|c|c|c|c|c|}
\hline \multirow[b]{2}{*}{ Portfolio } & \multicolumn{10}{|c|}{ Forecast horizon (months) } \\
\hline & $1-2$ & $3-4$ & $5-6$ & $7-8$ & $9-10$ & $11-12$ & $13-14$ & $15-16$ & $17-18$ & Sum \\
\hline \multicolumn{11}{|c|}{ Panel A: Lagged 1-year returns } \\
\hline & \multicolumn{10}{|c|}{$\beta \times 100$} \\
\hline Small & 2.1 & -0.7 & -1.2 & -2.0 & $-3.3 *$ & $-3.7 *$ & $-4.1^{*}$ & $-2.8^{*}$ & -2.7 & -18.3 \\
\hline 2 & 0.5 & -1.8 & -1.5 & -1.8 & $-3.3 *$ & $-3.5^{*}$ & $-3.7 *$ & -2.2 & -2.7 & -20.0 \\
\hline 3 & 0.1 & -2.3 & -2.0 & -2.6 & $-3.7^{*}$ & $-3.8^{*}$ & $-3.7 *$ & -1.9 & -2.0 & -21.9 \\
\hline 4 & -0.6 & -2.8 & -2.2 & -2.6 & $-3.8^{*}$ & $-4.0^{*}$ & $-4.0^{*}$ & -2.1 & -2.4 & $-24.6^{*}$ \\
\hline 5 & -1.0 & -3.1 & -2.1 & -2.6 & $-3.9 *$ & $-4.0^{*}$ & $-3.6^{*}$ & -1.5 & -2.0 & $-23.9 *$ \\
\hline 6 & -1.2 & -3.4 & -2.7 & -3.0 & $-3.9 *$ & $-4.3 *$ & $-3.5^{*}$ & -1.3 & -1.6 & $-24.8 *$ \\
\hline 7 & -1.6 & -3.4 & -2.9 & $-3.5^{*}$ & $-4.7 *$ & $-5.0 *$ & $-4.2 *$ & -2.1 & -2.2 & $-29.7 *$ \\
\hline 8 & -1.2 & -3.3 & -2.9 & $-3.8^{*}$ & $-4.8^{*}$ & $-4.9 *$ & $-4.1 *$ & -1.8 & -1.8 & $-28.6^{*}$ \\
\hline 9 & -2.4 & $-4.2 *$ & -3.5 & $-3.9 *$ & $-4.9 *$ & $-4.9 *$ & $-4.0^{*}$ & -1.8 & -1.7 & $-31.2 *$ \\
\hline 10 & -2.2 & -3.2 & -2.6 & -3.2 & $-4.2 *$ & $-4.6^{*}$ & $-3.8^{*}$ & -1.9 & -2.1 & $-27.7 *$ \\
\hline 11 & -1.6 & -2.7 & -2.6 & $-3.4^{*}$ & $-4.3^{*}$ & $-4.5^{*}$ & $-3.4^{*}$ & -1.1 & -1.1 & $-24.7 *$ \\
\hline Large & 1.1 & 0.4 & -0.3 & -0.9 & -2.8 & -3.3 & $-3.6^{*}$ & -1.9 & -1.5 & -12.8 \\
\hline VW index & -0.8 & -1.9 & -2.0 & -2.7 & $-4.2 *$ & $-4.6^{*}$ & $-4.3^{*}$ & -2.1 & -1.9 & $-24.5^{*}$ \\
\hline EW index & 0.5 & -2.0 & -2.1 & -2.7 & $-3.9 *$ & $-4.1^{*}$ & $-4.1 *$ & -2.2 & -2.0 & $-22.6 *$ \\
\hline Ave. size port & -1.0 & -3.1 & -2.7 & $-3.3^{*}$ & $-4.6^{*}$ & $-4.8^{*}$ & $-4.4^{*}$ & -2.4 & -2.5 & $-28.7 *$ \\
\hline \multirow[t]{2}{*}{ Average $\beta$} & -0.7 & -2.5 & -2.2 & -2.8 & $-4.0 *$ & $-4.2 *$ & $-3.8^{*}$ & -1.9 & -2.0 & $-24.0 *$ \\
\hline & \multicolumn{10}{|c|}{ std error $\times 100$} \\
\hline Small & 1.9 & 1.9 & 1.8 & 1.7 & 1.6 & 1.6 & 1.7 & 1.6 & 1.7 & 12.0 \\
\hline 2 & 2.1 & 2.1 & 2.1 & 1.9 & 1.8 & 1.8 & 1.9 & 1.8 & 1.9 & 13.1 \\
\hline 3 & 2.1 & 2.1 & 2.1 & 1.9 & 1.8 & 1.8 & 1.9 & 1.8 & 1.9 & 13.2 \\
\hline 4 & 2.1 & 2.2 & 2.1 & 1.9 & 1.8 & 1.8 & 2.0 & 1.8 & 2.0 & 13.3 \\
\hline 5 & 2.2 & 2.2 & 2.1 & 1.9 & 1.9 & 1.9 & 2.0 & 1.9 & 2.0 & 13.3 \\
\hline 6 & 2.1 & 2.2 & 2.1 & 1.9 & 1.8 & 1.8 & 1.9 & 1.8 & 1.9 & 12.8 \\
\hline 7 & 2.2 & 2.3 & 2.2 & 2.0 & 1.9 & 2.0 & 2.1 & 2.0 & 2.0 & 13.9 \\
\hline 8 & 2.2 & 2.2 & 2.1 & 1.9 & 1.9 & 1.9 & 2.0 & 1.9 & 2.0 & 13.6 \\
\hline 9 & 2.3 & 2.3 & 2.2 & 2.0 & 2.0 & 1.9 & 2.1 & 1.9 & 2.0 & 13.8 \\
\hline 10 & 2.4 & 2.4 & 2.3 & 2.1 & 2.1 & 2.2 & 2.3 & 2.2 & 2.2 & 15.0 \\
\hline 11 & 2.4 & 2.3 & 2.2 & 2.0 & 2.1 & 2.1 & 2.1 & 2.0 & 2.1 & 14.5 \\
\hline Large & 2.5 & 2.3 & 2.2 & 2.2 & 2.2 & 2.2 & 2.2 & 2.1 & 2.1 & 15.8 \\
\hline VW index & 2.4 & 2.3 & 2.2 & 2.1 & 2.1 & 2.1 & 2.2 & 2.0 & 2.0 & 14.7 \\
\hline EW index & 2.1 & 2.1 & 2.0 & 1.8 & 1.7 & 1.8 & 1.9 & 1.8 & 1.9 & 12.8 \\
\hline Ave. size port & 2.2 & 2.2 & 2.1 & 1.9 & 1.9 & 1.9 & 2.0 & 1.9 & 1.9 & 13.4 \\
\hline Average $\beta$ & 2.0 & 2.1 & 2.0 & 1.8 & 1.8 & 1.8 & 1.9 & 1.7 & 1.8 & 12.5 \\
\hline
\end{tabular}

* Estimate is significant at the 5\% level (one-sided) based on bootstrap simulations. 
Table 4

Monthly regressions, 1946 - 1998 (continued)

\begin{tabular}{|c|c|c|c|c|c|c|c|c|c|c|}
\hline \multirow[b]{2}{*}{ Portfolio } & \multicolumn{10}{|c|}{ Forecast horizon (months) } \\
\hline & $1-2$ & $3-4$ & $5-6$ & $7-8$ & $9-10$ & $11-12$ & $13-14$ & $15-16$ & $17-18$ & Sum \\
\hline \multicolumn{11}{|c|}{ Panel B: Lagged 3-year returns } \\
\hline & \multicolumn{10}{|c|}{$\beta \times 100$} \\
\hline Small & 0.3 & 0.1 & -0.1 & -0.4 & -0.5 & -0.4 & -0.4 & -0.4 & -0.4 & -2.0 \\
\hline 2 & -0.1 & -0.2 & -0.5 & -0.8 & -0.9 & -0.8 & -0.8 & -0.6 & -0.6 & -5.3 \\
\hline 3 & -0.4 & -0.7 & -1.0 & -1.3 & $-1.4^{*}$ & -1.2 & -1.1 & -0.7 & -0.7 & -8.5 \\
\hline 4 & -1.1 & -1.3 & -1.4 & -1.5 & $-1.5^{*}$ & -1.4 & $-1.4 *$ & -0.7 & -0.7 & -11.0 \\
\hline 5 & -1.2 & -1.2 & -1.3 & $-1.6^{*}$ & $-1.7 *$ & -1.5 & -1.3 & -0.6 & -0.6 & -10.9 \\
\hline 6 & -1.2 & -1.4 & -1.6 & $-1.9 *$ & $-1.8^{*}$ & $-1.5^{*}$ & -1.3 & -0.5 & -0.4 & -11.6 \\
\hline 7 & -1.8 & -1.9 & $-2.0 *$ & $-2.1 *$ & $-2.1^{*}$ & $-1.8^{*}$ & $-1.6^{*}$ & -0.7 & -0.5 & -14.3 \\
\hline 8 & -1.7 & -1.8 & $-2.0 *$ & $-2.2 *$ & $-2.2 *$ & $-1.8^{*}$ & -1.6 & -0.4 & -0.1 & -13.6 \\
\hline 9 & -2.2 & $-2.4 *$ & $-2.5 *$ & $-2.6^{*}$ & $-2.6^{*}$ & $-2.2 *$ & $-2.0 *$ & -0.6 & 0.0 & -17.2 \\
\hline 10 & -2.3 & -2.1 & -2.1 & -2.1 & $-2.1^{*}$ & -1.9 & -1.7 & -0.4 & -0.1 & -14.6 \\
\hline 11 & -1.3 & -1.3 & -1.4 & -1.7 & -1.7 & -1.3 & -1.1 & 0.1 & 0.5 & -9.2 \\
\hline Large & -0.2 & 0.0 & -0.4 & -0.4 & -0.7 & -0.5 & -0.6 & 0.5 & 1.0 & -1.3 \\
\hline VW index & -1.4 & -1.3 & -1.5 & -1.6 & -1.7 & -1.5 & -1.4 & 0.0 & 0.5 & -9.9 \\
\hline EW index & -0.5 & -0.7 & -1.0 & -1.2 & -1.4 & -1.2 & -1.2 & -0.5 & -0.5 & -8.2 \\
\hline Ave. size port & -1.4 & -1.4 & -1.6 & $-1.8^{*}$ & $-1.8^{*}$ & $-1.6^{*}$ & $-1.5^{*}$ & -0.8 & -0.7 & -12.5 \\
\hline \multirow[t]{2}{*}{ Average $\beta$} & -1.1 & -1.2 & -1.4 & $-1.5^{*}$ & $-1.6^{*}$ & $-1.4 *$ & -1.2 & -0.4 & -0.2 & -9.9 \\
\hline & \multicolumn{10}{|c|}{ std error $\times 100$} \\
\hline Small & 0.8 & 0.6 & 0.6 & 0.6 & 0.5 & 0.5 & 0.5 & 0.4 & 0.4 & 4.7 \\
\hline 2 & 1.0 & 0.9 & 0.9 & 0.8 & 0.8 & 0.7 & 0.7 & 0.7 & 0.7 & 6.8 \\
\hline 3 & 1.0 & 1.0 & 0.9 & 0.9 & 0.9 & 0.9 & 0.8 & 0.8 & 0.8 & 7.5 \\
\hline 4 & 1.2 & 1.1 & 1.0 & 1.0 & 1.0 & 0.9 & 0.9 & 0.9 & 0.9 & 8.1 \\
\hline 5 & 1.1 & 1.1 & 1.0 & 1.0 & 1.0 & 0.9 & 0.9 & 0.9 & 0.9 & 8.0 \\
\hline 6 & 1.1 & 1.1 & 1.0 & 1.0 & 1.0 & 0.9 & 0.9 & 0.9 & 0.9 & 8.0 \\
\hline 7 & 1.3 & 1.2 & 1.2 & 1.1 & 1.1 & 1.0 & 1.0 & 1.0 & 0.9 & 8.8 \\
\hline 8 & 1.3 & 1.3 & 1.2 & 1.1 & 1.1 & 1.1 & 1.0 & 1.0 & 1.0 & 9.0 \\
\hline 9 & 1.4 & 1.4 & 1.3 & 1.2 & 1.1 & 1.1 & 1.1 & 1.1 & 1.1 & 9.3 \\
\hline 10 & 1.5 & 1.5 & 1.4 & 1.3 & 1.2 & 1.2 & 1.2 & 1.1 & 1.1 & 10.2 \\
\hline 11 & 1.4 & 1.4 & 1.3 & 1.2 & 1.1 & 1.1 & 1.1 & 1.1 & 1.1 & 9.5 \\
\hline Large & 1.3 & 1.3 & 1.3 & 1.2 & 1.1 & 1.1 & 1.2 & 1.1 & 1.1 & 9.6 \\
\hline VW index & 1.4 & 1.4 & 1.3 & 1.2 & 1.2 & 1.1 & 1.1 & 1.1 & 1.1 & 9.6 \\
\hline EW index & 1.1 & 1.0 & 1.0 & 0.9 & 0.9 & 0.9 & 0.9 & 0.9 & 0.8 & 7.7 \\
\hline Ave. size port & 1.2 & 1.1 & 1.1 & 1.0 & 1.0 & 0.9 & 0.9 & 0.9 & 0.8 & 8.1 \\
\hline Average $\beta$ & 1.1 & 1.0 & 1.0 & 0.9 & 0.9 & 0.8 & 0.8 & 0.8 & 0.8 & 7.3 \\
\hline
\end{tabular}

* Estimate is significant at the $5 \%$ level (one-sided) based on bootstrap simulations. 
Table 4

Monthly regressions, 1946 - 1998 (continued)

\begin{tabular}{|c|c|c|c|c|c|c|c|c|c|c|}
\hline \multirow[b]{2}{*}{ Portfolio } & \multicolumn{10}{|c|}{ Forecast horizon (months) } \\
\hline & $1-2$ & $3-4$ & $5-6$ & $7-8$ & $9-10$ & $11-12$ & $13-14$ & $15-16$ & $17-18$ & Sum \\
\hline \multicolumn{11}{|c|}{ Panel C: Lagged 5-year returns } \\
\hline & \multicolumn{10}{|c|}{$\beta \times 100$} \\
\hline Small & 0.1 & 0.0 & 0.0 & 0.0 & -0.1 & -0.1 & -0.1 & -0.1 & 0.0 & -0.3 \\
\hline 2 & -0.2 & -0.4 & -0.3 & -0.3 & -0.4 & -0.5 & -0.5 & -0.5 & -0.4 & -3.4 \\
\hline 3 & -0.4 & -0.6 & -0.5 & -0.5 & -0.6 & $-0.7^{*}$ & $-0.7 *$ & -0.6 & -0.5 & -5.2 \\
\hline 4 & -0.5 & -0.9 & -0.7 & -0.7 & -0.7 & -0.8 & $-0.9 *$ & -0.7 & -0.6 & -6.4 \\
\hline 5 & -0.5 & -0.8 & -0.5 & -0.6 & -0.6 & -0.7 & -0.8 & -0.6 & -0.5 & -5.6 \\
\hline 6 & -0.6 & -0.9 & -0.6 & -0.6 & -0.6 & -0.6 & -0.7 & -0.5 & -0.4 & -5.4 \\
\hline 7 & -0.8 & -1.1 & -0.8 & -0.7 & -0.7 & -0.8 & -0.9 & -0.6 & -0.4 & -6.8 \\
\hline 8 & -0.5 & -0.9 & -0.6 & -0.6 & -0.6 & -0.6 & -0.5 & -0.3 & -0.1 & -4.8 \\
\hline 9 & -0.7 & -1.1 & -0.7 & -0.6 & -0.5 & -0.5 & -0.5 & -0.3 & 0.0 & -5.1 \\
\hline 10 & -0.6 & -0.8 & -0.4 & -0.3 & -0.2 & -0.3 & -0.4 & -0.3 & -0.1 & -3.4 \\
\hline 11 & -0.1 & -0.3 & -0.1 & -0.1 & 0.0 & 0.1 & 0.1 & 0.3 & 0.6 & 0.4 \\
\hline Large & 0.8 & 0.6 & 0.6 & 0.6 & 0.7 & 0.7 & 0.4 & 0.5 & 0.6 & 5.2 \\
\hline VW index & 0.0 & -0.2 & 0.0 & 0.0 & 0.1 & 0.2 & 0.0 & 0.1 & 0.3 & 0.5 \\
\hline EW index & -0.2 & -0.5 & -0.4 & -0.5 & -0.6 & -0.6 & -0.7 & -0.6 & -0.5 & -4.6 \\
\hline Ave. size port & -0.5 & -0.8 & -0.6 & -0.6 & -0.6 & -0.7 & -0.7 & -0.6 & -0.4 & -5.6 \\
\hline \multirow[t]{2}{*}{ Average $\beta$} & -0.3 & -0.6 & -0.4 & -0.4 & -0.4 & -0.4 & -0.5 & -0.3 & -0.1 & -3.4 \\
\hline & \multicolumn{10}{|c|}{ std error $\times 100$} \\
\hline Small & 0.2 & 0.2 & 0.2 & 0.2 & 0.2 & 0.2 & 0.2 & 0.2 & 0.2 & 1.5 \\
\hline 2 & 0.4 & 0.4 & 0.4 & 0.4 & 0.4 & 0.4 & 0.4 & 0.4 & 0.3 & 3.2 \\
\hline 3 & 0.5 & 0.5 & 0.5 & 0.5 & 0.5 & 0.5 & 0.5 & 0.5 & 0.4 & 4.1 \\
\hline 4 & 0.6 & 0.6 & 0.6 & 0.6 & 0.6 & 0.5 & 0.5 & 0.5 & 0.5 & 4.7 \\
\hline 5 & 0.6 & 0.7 & 0.6 & 0.6 & 0.6 & 0.6 & 0.6 & 0.6 & 0.5 & 4.9 \\
\hline 6 & 0.6 & 0.7 & 0.6 & 0.6 & 0.6 & 0.6 & 0.6 & 0.6 & 0.5 & 4.9 \\
\hline 7 & 0.8 & 0.8 & 0.8 & 0.7 & 0.7 & 0.7 & 0.7 & 0.7 & 0.6 & 5.8 \\
\hline 8 & 0.8 & 0.8 & 0.8 & 0.8 & 0.7 & 0.7 & 0.7 & 0.7 & 0.7 & 6.2 \\
\hline 9 & 0.9 & 0.9 & 0.9 & 0.8 & 0.8 & 0.8 & 0.8 & 0.7 & 0.7 & 6.5 \\
\hline 10 & 0.9 & 1.0 & 0.9 & 0.9 & 0.8 & 0.8 & 0.8 & 0.8 & 0.8 & 7.1 \\
\hline 11 & 0.8 & 0.9 & 0.8 & 0.8 & 0.8 & 0.7 & 0.7 & 0.7 & 0.7 & 6.5 \\
\hline Large & 0.9 & 0.9 & 0.9 & 0.8 & 0.8 & 0.7 & 0.7 & 0.7 & 0.7 & 6.7 \\
\hline VW index & 0.9 & 1.0 & 0.9 & 0.9 & 0.8 & 0.8 & 0.8 & 0.8 & 0.7 & 7.0 \\
\hline EW index & 0.6 & 0.6 & 0.5 & 0.5 & 0.5 & 0.5 & 0.5 & 0.5 & 0.5 & 4.3 \\
\hline Ave. size port & 0.6 & 0.6 & 0.6 & 0.6 & 0.5 & 0.5 & 0.5 & 0.5 & 0.5 & 4.4 \\
\hline Average $\beta$ & 0.6 & 0.6 & 0.6 & 0.6 & 0.5 & 0.5 & 0.5 & 0.5 & 0.5 & 4.6 \\
\hline
\end{tabular}

* Estimate is significant at the $5 \%$ level (one-sided) based on bootstrap simulations. 
Table 5

Predictive power of 1-year returns in various subperiods

The table reports bias-adjusted slope coefficients and Newey-West (1987) standard errors when either 12month returns (Panel A) or 18-month returns (Panel B) are regressed on lagged annual returns. The table shows estimates for 1932 - 1945, 1946 - 1971, and 1972 - 1998. The coefficients are estimated from OLS regressions with overlapping monthly observations, and bias and significance levels are obtained from bootstrap simulations. The table reports estimates for 12 size portfolios, equal- and value-weighted market indices, and the equal-weighted average of the size portfolios.

\begin{tabular}{|c|c|c|c|c|c|c|}
\hline \multirow[b]{2}{*}{ Portfolio } & \multicolumn{3}{|c|}{ Slope estimate } & \multicolumn{3}{|c|}{ Std error } \\
\hline & $1932-45$ & $1946-71$ & $1972-98$ & $1932-45$ & $1946-71$ & 1972-98 \\
\hline \multicolumn{7}{|c|}{ Panel A: Autocorrelations } \\
\hline Small & -0.03 & -0.10 & -0.03 & 0.08 & 0.13 & 0.16 \\
\hline 2 & -0.04 & -0.13 & -0.07 & 0.09 & 0.12 & 0.16 \\
\hline 3 & -0.12 & -0.14 & -0.13 & 0.11 & 0.12 & 0.17 \\
\hline 4 & -0.14 & -0.15 & -0.16 & 0.11 & 0.12 & 0.17 \\
\hline 5 & -0.19 & -0.20 & -0.13 & 0.12 & 0.11 & 0.18 \\
\hline 6 & -0.14 & -0.23 & -0.14 & 0.12 & 0.12 & 0.18 \\
\hline 7 & -0.20 & -0.23 & -0.20 & 0.12 & 0.11 & 0.19 \\
\hline 8 & -0.20 & -0.21 & -0.20 & 0.12 & 0.12 & 0.18 \\
\hline 9 & -0.14 & -0.25 & -0.24 & 0.13 & 0.11 & 0.17 \\
\hline 10 & -0.19 & -0.23 & -0.16 & 0.13 & 0.13 & 0.17 \\
\hline 11 & -0.16 & -0.22 & -0.16 & 0.13 & 0.12 & 0.16 \\
\hline Large & -0.22 & -0.06 & -0.05 & 0.13 & 0.15 & 0.14 \\
\hline VW index & -0.21 & -0.15 & -0.17 & 0.13 & 0.14 & 0.15 \\
\hline EW index & -0.13 & -0.17 & -0.10 & 0.11 & 0.12 & 0.16 \\
\hline Ave. size portfolio & -0.13 & -0.20 & -0.18 & 0.11 & 0.11 & 0.18 \\
\hline Average $\beta$ & -0.15 & -0.18 & -0.14 & 0.11 & 0.11 & 0.16 \\
\hline \multicolumn{7}{|c|}{ Panel B: Predicting 18-month returns } \\
\hline Small & -0.03 & -0.26 & -0.01 & 0.10 & 0.14 & 0.22 \\
\hline 2 & -0.04 & -0.24 & -0.06 & 0.11 & 0.14 & 0.21 \\
\hline 3 & -0.10 & -0.25 & -0.12 & 0.11 & 0.14 & 0.21 \\
\hline 4 & -0.14 & -0.27 & -0.16 & 0.12 & 0.14 & 0.21 \\
\hline 5 & -0.24 & -0.30 & -0.12 & 0.12 & 0.14 & 0.22 \\
\hline 6 & -0.16 & -0.33 & -0.11 & 0.11 & 0.14 & 0.21 \\
\hline 7 & -0.25 & $-0.34 *$ & -0.23 & 0.13 & 0.13 & 0.22 \\
\hline 8 & -0.20 & -0.29 & -0.25 & 0.12 & 0.15 & 0.22 \\
\hline 9 & -0.12 & $-0.33 *$ & -0.29 & 0.14 & 0.13 & 0.19 \\
\hline 10 & -0.16 & -0.29 & -0.24 & 0.11 & 0.16 & 0.21 \\
\hline 11 & -0.15 & -0.28 & -0.21 & 0.15 & 0.15 & 0.20 \\
\hline Large & -0.23 & -0.12 & -0.16 & 0.12 & 0.18 & 0.19 \\
\hline VW index & -0.21 & -0.23 & -0.28 & 0.13 & 0.16 & 0.18 \\
\hline EW index & -0.14 & -0.30 & -0.12 & 0.12 & 0.14 & 0.21 \\
\hline Ave. size portfolio & -0.13 & -0.32 & -0.22 & 0.12 & 0.14 & 0.21 \\
\hline Average $\beta$ & -0.15 & -0.27 & -0.16 & 0.11 & 0.13 & 0.19 \\
\hline
\end{tabular}

* Estimate is significant at the $5 \%$ level (one-sided) based on bootstrap simulations. 